\title{
Removal of hexavalent chromium of contaminated soil by coupling electrokinetic remediation and permeable reactive biobarriers
}

\author{
B. Fonseca • M. Pazos • T. Tavares • M. A. Sanromán
}

Received: 17 November 2011 / Accepted: 9 December 2011 /Published online: 28 December 2011

(C) Springer-Verlag 2011

\begin{abstract}
Purpose In this study, a novel and ecological alternative have been developed to treat soils contaminated with hexavalent chromium coupling two well-known systems: electrokinetic remediation and permeable reactive biobarriers. The electric field promotes the electromigration of the hexavalent chromium oxyanions towards the anode. The biobarriers were placed before the anode electrode, in order to promote the reduction and retention of the chromium migrating in its direction. Thus, this technology provided a global treatment to soil removal without subsequent treatments of the contaminated effluents.

Methods The electrokinetic system was coupled with two different permeable reactive biobarriers composed by Arthrobacter viscosus bacteria, supported either in activated carbon or zeolite. An electric field of $10 \mathrm{~V}$ was applied and two different treatment times of 9 and 18 days were tested. Results Removal values of $60 \%$ and $79 \%$ were obtained when electrokinetic treatment was coupled with zeolite and activated carbon biobarriers, respectively, for a test period of 18 day. The reduction of hexavalent chromium to trivalent chromium was around $45 \%$ for both systems.

Conclusions In this work, two types of biobarriers were efficiently coupled to electrokinetic treatment to decontaminate soil with $\mathrm{Cr}(\mathrm{VI})$. Furthermore, the viability of the new
\end{abstract}

Responsible editor Vinod Kumar Gupta

B. Fonseca $\cdot$ T. Tavares

IBB-Institute for Biotechnology and Bioengineering,

Centre of Biological Engineering, University of Minho,

4710-057 Braga, Portugal

M. Pazos $(\bowtie) \cdot$ M. A. Sanromán

Department of Chemical Engineering, University of Vigo,

36310 Vigo, Spain

e-mail: mcurras@uvigo.es coupling technology developed (electrokinetic + biobarriers) to treat low-permeability polluted soils was demonstrated.

Keywords Chromium · Soils · Bioremediation · Biosorption - Electrokinetic remediation - Activated carbon . Zeolite

\section{Introduction}

Hexavalent chromium, $\mathrm{Cr}(\mathrm{VI})$, is extensively used in a wide range of industrial activities, like manufacturing of stainless steel, chrome leather tanning, ceramics, pyrotechnics and electronics. It is frequently released to waters and soils, due to accidental spills, storm water run-off and uncontrolled leaching from storage ponds or dumps. Moreover, it is known as one of the most toxic heavy metals, being in evidence in the EPA list of human carcinogens and designated as a priority pollutant in many countries (Fonseca et al. 2009). The main effects of chromium metal ions are on liver, kidney, and respiratory organs, with hemorrhagic effects, dermatitis, and ulceration of the skin for chronic and subcronic exposure (Gupta et al. 1999). Concentrations greater than $50 \mu \mathrm{g} \mathrm{L}^{-1}$ are sufficient grounds for the rejection of the water supply (Gupta et al. 2006). For this reason, it is necessary to develop new methods of analysis and remediation of chromium. Taking in account the large number of environmental samples, a fast, and low cost analysis methods, such as analysis chromium selective sensors is a promising method that gained important credibility (Gupta et al. 2006; Singh et al. 2007). In chromium remediation, several techniques have been developed to treat contaminated soils, like flushing, phytoremediation, excavation and landfill disposal. However, for over a decade, the removal of metals, such us $\mathrm{Cr}(\mathrm{VI})$, from soils through the operation 
of electrokinetic remediation has attracted significant attention. Basically, this technique promotes the electromigration of the $\mathrm{Cr}(\mathrm{VI})$ oxyanions towards the anode chamber, when a low voltage gradient is applied (Reddy and Chinthamreddy 2003; Pazos et al. 2009). This technology can be applied in situ or ex situ, with cost effectiveness; however, there are some problems concerning this method, like its elongation in time and the production of contaminated liquid effluents (Baraud et al. 1997b; Teutli-León et al. 2005).

Nowadays, the use of permeable reactive barriers (PRBs) has gained popularity in the groundwater treatment field, due to its high efficiency, low cost and simple operation procedures. These barriers are composed by reactive materials that once in contact with the contaminated water plume, can degrade, adsorb or precipitate the targeted contaminants (Viamajala et al. 2008; Boni and Sbaffoni 2009). Due to the evolution of biotechnology, biologic materials are being successfully used in these PRBs forming permeable reactive biobarriers. The action of these barriers is based on the initial stage of sorption or biosorption process, which represents a cost effective excellent tool for removing heavy metals from aqueous solutions (Ali and Gupta 2007; Cristani et al. 2011; Priyantha and Bandaranayaka 2011). Recent investigations by various researchers have shown that several solid waste materials (red mud, bagasse fly ash, carbon slurry) generated in some prime industries, are efficient adsorbents for the removal of heavy metals such as lead and chromium (Gupta et al. 1999, 2001; Gupta and Ali 2004; Gupta et al. 2010). In addition, the application of composites materials as adsorbents is considered. An example is the use a magnetic adsorbent obtained by composite of multiwall carbon nanotubes with the magnetic properties of iron oxides. The advantage of this magnetic composite is that it can be used as adsorbent for contaminants in water and can be subsequently controlled and removed from the medium by a simple magnetic process (Gupta et al. 2011).

On the other hand, biosorption on materials of biological origin has been proposed as a potential alternative. It has gained important credibility during recent years because of its ecofriendly nature, excellent performance, and low cost domestic technique for remediating even, heavily metal loaded wastewater. New approaches of developing various microbial sources, seaweed, aquatic plants and leaf based adsorbents as cost effective and efficient biosorbents have been reported (Gupta and Rastogi 2008, 2009). In this sense, previous experiments using Arthrobacter viscosus supported either in zeolites or activated carbon, showed to be an efficient adsorbent in the treatment of $\mathrm{Cr}(\mathrm{VI})$ effluents. Succinctly, when these systems are applied, $\mathrm{Cr}(\mathrm{VI})$ is reduced by the bacteria to the trivalent form, $\mathrm{Cr}(\mathrm{III})$, which is entrapped in the physical support by adsorption or ion exchange (Quintelas and Tavares 2001; Silva et al. 2008; Quintelas et al. 2009; Figueiredo et al. 2010a; Pazos et al.
2010). This biosorption mechanism is known as the "adsorption coupled reduction". $\mathrm{Cr}(\mathrm{III})$ is a less soluble, mobile and toxic form of chromium, and above all this, it is an essential micronutrient (Fendorf 1995; Silva et al. 2009). Furthermore, these biosorbents containing the immobilized chromium can then be used as catalysts (Figueiredo et al. 2010c).

The implementation of sustainable or improved technologies that combine efficiency and economy has become a requirement for environmental preservation due to the growing presence of contaminants from industrial discharge. This calls for a clearer understanding of the scientific and technical aspects of these technologies to improve their sustainability. In this sense, research has shown that the efficiency of several processes can be improved if they are combined with a complementary method. In the remediation of heavy metals and organic pollutants several combined methodology have been tested such as electrocoagulation and electrodialysis techniques, biodegradation and ozonation, electrochemical and chemical processes (Ali et al. 2011; Kanagaraj and Mandal 2011; Machado et al. 2011). The use of these combined technologies circumvents the limitations of the individual technologies and yields a synergistic effect that improves the efficiency of contaminant removal.

Based on the above-mentioned knowledge, this work aims to evaluate the application of an innovative combined system, which couples electrokinetic remediation with specific permeable reactive biobarriers, to treat low-permeability soils contaminated with $\mathrm{Cr}(\mathrm{VI})$. The biosorbents selected as biobarriers are generated by the bacterium $A$. viscosus immobilized on porous materials such as Zeolite $13 \mathrm{X}$ or on activated carbon.

\section{Material and methods}

\subsection{Material}

Contaminant The potassium dichromate $\left(\mathrm{K}_{2} \mathrm{Cr}_{2} \mathrm{O}_{7}\right)$ used to contaminate the soil was purchased from Normapur AR.

Soil The soil selected for this research was the clay mineral kaolin, since it represents a low-permeability soil, with consistent and uniform mineralogy and low cation exchange and buffering capacities. The composition and properties of this soil were summarized elsewhere (Alcantara et al. 2008).

Bacteria A. viscosus was obtained from the Spanish Type Culture Collection of the University of Valencia. It was maintained at $4^{\circ} \mathrm{C}$ on $15 \mathrm{gL}^{-1}$ agar slants and plates with culture medium containing, in grams per liter, 10 of glucose, 5 of peptone, 3 of malt extract and 3 of yeast extract. 
Supports Activated carbon was purchased from MERCK. It was characterized by an average particle size of $2.5 \mathrm{~mm}$, a Langmuir area of $1270 \mathrm{~m}^{2} \mathrm{~g}^{-1}$ and an average pore diameter of $2 \mathrm{~nm}$ (Quintelas et al. 2008). The Zeolite 13X was provided by Xiamen Zhongzhao Imp. \& Exp. The pellets size was $5-8 \mathrm{~mm}$ and normal pore diameter $13 \AA$. Both supports were macerated with the purpose of working with their powder.

\subsection{Soil preparation}

The soil was spiked with $\mathrm{K}_{2} \mathrm{Cr}_{2} \mathrm{O}_{7}$ solution, in order to obtain a concentration of $\mathrm{Cr}(\mathrm{VI})$ around $50 \mathrm{mg} \mathrm{kg}^{-1}$. The quantity required to obtain the desired concentration, was dissolved in a volume of water. The mixture was placed in a fume hood and stirred every day, till complete dryness (2-3 days). Then, the soil was mixed with water to obtain a moisture content of $30 \%(w / w)$. The mixture was performed in a glass vat with stirring rod. At the end, a sample was collected to determine the initial concentration of $\mathrm{Cr}(\mathrm{VI})$.

\subsection{Biobarriers preparation}

A volume of $500 \mathrm{~mL}$ of culture medium for $A$. viscosus was prepared. Then, the zeolite or the activated carbon, were added in order to obtain the same ratio of solid/solution $(v / v)$ for both supports $(1: 12.5)$. This decision was supported by previous works performed with the same supports (Quintelas et al. 2008; Figueiredo et al. 2010a, b). Each set was sterilized at $121^{\circ} \mathrm{C}$ for $20 \mathrm{~min}$, cooled to room temperature, inoculated with bacteria and kept at $28^{\circ} \mathrm{C}$ for $48 \mathrm{~h}$. The volume of the growth culture, together with the support, was filtered by using a mechanical vacuum system with cellulose filters (Whatman, Ø $32 \mathrm{~mm}$ ). The pairing of two filters, containing biomass supported on zeolite or carbon, constituted a "biobarrier".

\subsection{Experimental setup}

The experiments correspondent to the blank assays were performed in glass cells (Fig. 1) with $13.5 \mathrm{~cm}$ of length and $32 \mathrm{~mm}$ of diameter (Pazos et al. 2008), filled with the contaminated kaolin. Then, a cathode and anode electrode chambers (with $300 \mathrm{~mL}$ working volume) were coupled at the ends of the column, isolated from the matrix with filter papers and porous stones. Graphite electrodes were used for both chambers and three auxiliary electrodes allowed the measurement of the electric field through the column. The electrode chambers were filled with distilled water and the liquid was recirculated, by peristaltic pumps, to prevent the development of concentration gradients. The $\mathrm{pH}$ in both chambers was controlled in order to maintain it around 5, which is a value that represents a commitment between the

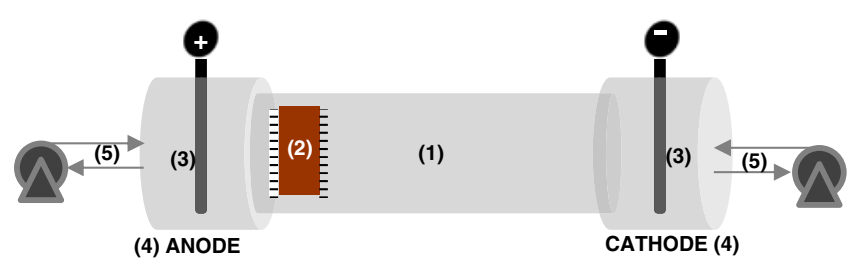

Fig. 1 Schematic diagram of experimental setup: (1) soil sample, (2) biobarrier between porous stones, (3) electrodes, (4) electrode chambers, (5) recirculation pumps.

optimum $\mathrm{pH}$ for the bacterium and the optimum $\mathrm{pH}$ for the $\mathrm{Cr}$ (III) adsorption by each support (Silva et al. 2009; Pazos et al. 2010). The adjustment was made with $\mathrm{NaOH}(0.1 \mathrm{M})$ and $\mathrm{HNO}_{3}(2 \mathrm{M})$ for anode and cathode chambers, respectively. A potential difference of $10 \mathrm{~V}$ was applied to the horizontal column. Readings of voltage drop and current intensity were made periodically. Since the dichromate anions migrate towards the anode chamber, as proved by the blank assays results, the tests with biobarriers were performed by inserting the biobarrier, comprised between two filter papers and two porous stones, before this compartment. All the tests either blank or with carbon or zeolite biobarriers, were performed for two time intervals, 9 and 18 day, aiming the optimization of the decontamination process. Table 1 resumes the various experimental setups.

After each experiment, the soil sample was divided in five sections (S1 to S5). These samples, the biobarrier and the liquids from the electrode chambers were analyzed for total and hexavalent chromium, after $\mathrm{pH}$ determination.

The chromium uptake was calculated using the following equation:

$q=\left(C_{i}-C_{f}\right) \cdot V / M$

where $q$ is the chromium uptake (in milligrams per gram); $C_{\mathrm{i}}$ and $C_{\mathrm{f}}$ the initial concentration and the concentration through time (in milligrams per liter) respectively and $V$ is the solution volume (in liters).

\subsection{Analytical methods}

The analytical methods used to determine the total and the hexavalent chromium concentrations, on the liquid and solid phases and $\mathrm{pH}$ are listed below. All samples were processed in duplicate.

Total chromium The soil samples were digested in a microwave (CEM MDS-2000) with $\mathrm{HNO}_{3}(65 \%)$, according to the US EPA method 3051 (USEPA 2007). The determination of total chromium was made by flame atomic absorption (Varian SpectrAA-250 Plus). 
Table 1 Experimental conditions

\begin{tabular}{|c|c|c|c|c|c|}
\hline Assay & Treatment time (days) & Biobarrier & Electric field (V) & $\mathrm{pH}$ control A & $\mathrm{pH}$ control $\mathrm{C}$ \\
\hline 1 & 9 & Blank & 10 & $\mathrm{NaOH} 0.1 \mathrm{M}$ & $\mathrm{HNO}_{3} 2 \mathrm{M}$ \\
\hline 2 & 9 & Activated carbon & 10 & $\mathrm{NaOH} 0.1 \mathrm{M}$ & $\mathrm{HNO}_{3} 2 \mathrm{M}$ \\
\hline 3 & 9 & Zeolite & 10 & $\mathrm{NaOH} 0.1 \mathrm{M}$ & $\mathrm{HNO}_{3} 2 \mathrm{M}$ \\
\hline 4 & 18 & Blank & 10 & $\mathrm{NaOH} 0.1 \mathrm{M}$ & $\mathrm{HNO}_{3} 2 \mathrm{M}$ \\
\hline 5 & 18 & Activated carbon & 10 & $\mathrm{NaOH} 0.1 \mathrm{M}$ & $\mathrm{HNO}_{3} 2 \mathrm{M}$ \\
\hline 6 & 18 & Zeolite & 10 & $\mathrm{NaOH} 0.1 \mathrm{M}$ & $\mathrm{HNO}_{3} 2 \mathrm{M}$ \\
\hline
\end{tabular}

Hexavalent chromium Prior to the $\mathrm{Cr}(\mathrm{VI})$ determination on soil samples, an alkaline digestion of soil samples was performed as described on US EPA method 3060A (USEPA 1996). The quantification of $\mathrm{Cr}(\mathrm{VI})$ was made by the US EPA colorimetric method 7196A. The absorbance was measured using a Thermo He $\lambda$ ios $\beta$ spectrophotometer (USEPA 1992).

Trivalent chromium It was determined through the numerical difference between total and hexavalent chromium.

$\mathrm{pH}$ The $\mathrm{pH}$ of liquid samples was directly measured with a Jenway $3520 \mathrm{pH}$ meter, and the $\mathrm{pH}$ of soil samples was determined following the US EPA method 9045D (USEPA 2004).

\subsection{SEM analysis and bioviability}

The morphology and chemistry of the biobarrier after each test were analyzed by scanning electron microscopy (SEM). The microscope used was a Nova ${ }^{\mathrm{TM}} 200$ NanoSEM with an integrated electron-dispersive X-ray spectroscopy system (Pegasus X4M). The integrated system enabled simultaneous collection of data by an energy dispersive spectrometer and a back-scattered electron detector.

The bioviability of the $A$. viscosus was also tested at the end of the assays, by streaking in an agar plate containing the growth medium.

\section{Results and discussion}

Recently, electrokinetic remediation deserves particular attention to soil treatment due to its peculiar advantages, including the capability of treating fine and lowpermeability materials, and achieving consolidation, dewatering and removal of salts and inorganic contaminants in a single stage. Electrokinetic remediation is a widely advisable technology to treat slightly permeable soils, as sludge and sediments contaminated with heavy metals, anions and organic compounds in concentrations from a few up to thousands parts per million (ppm). To obtain high efficiency in the treatment of soil contaminated with organic and inorganic compounds several techniques have been coupled to electrokinetic remediation. In the present study, permeable reactive biobarriers, generated by biosorbents of $A$. viscosus immobilized on Zeolite $13 \mathrm{X}$ or on activated carbon, were placed before the anode electrode, in order to promote the reduction and retention of the chromium migrating in its direction. Thus, this technology provided a global treatment to soil removal without subsequent treatments of the contaminated effluents. In addition, the chromium is fixed in the biosorbent and after calcination this material can then be used as catalysts (Figueiredo et al. $2010 \mathrm{c}$ ), reducing the toxic wastes generated after the application of this treatment.

Taking into account the reduction of subsequent treatments and the value of the residue generated this combine technology suppose a novel technique to treat lowpermeability polluted soils with high advantages in comparison to the traditional methodologies. To our knowledge, there are not studies about the application of this combine technology and the overall topics mentioned above revealed the novelty of this study.

\subsection{Blank assay: evaluation of hexavalent chromium mobility}

In order to evaluate the mobility of the $\mathrm{Cr}(\mathrm{VI})$ in an electrokinetic treatment, two blank assays were performed for 9 and 18 days. As can be seen in Fig. 2, when the experiment lasted 9 days, low chromium mobility was detected and about $25 \%$ of chromium removal was achieved. Therefore, the time interval was elongated to the double, 18 day, and better results were obtained (Fig. 2). Additionally, the transport through the soil sample in this blank assay was toward the anode chamber. Figure 2 reveals that the higher percentage of $\mathrm{Cr}(\mathrm{VI})$ (approximately 77\%) was found in the anode chamber, which means that $\mathrm{Cr}(\mathrm{VI})$ oxyanions migrated toward this compartment. Consequently, the remaining contaminant on the kaolinite was gradually concentrated in the anode chamber direction. It should be noted that $100 \%$ of the initial $\mathrm{Cr}(\mathrm{VI})$ was recovered, from the different section of the electrokinetic cell, after the test.

The regular analysis of the anode chamber liquid revealed a growing concentration of $\mathrm{Cr}(\mathrm{VI})$ in this 


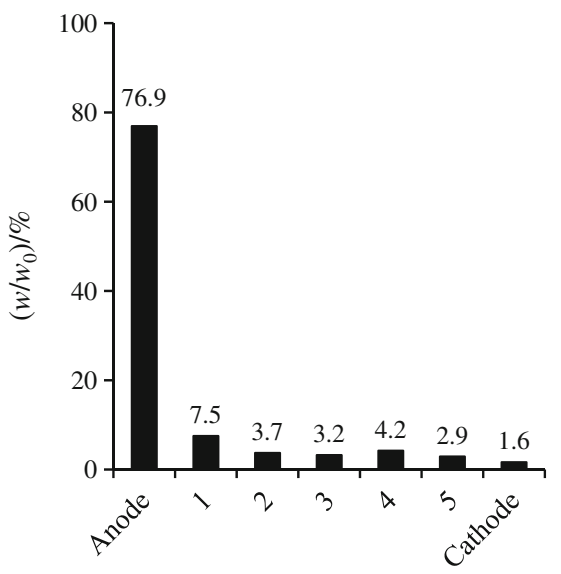

Fig. 2 Distribution of the percentage of hexavalent chromium with respect to the initial chromium weight $\left(w / w_{0}\right)$ across the electrokinetic cell—soil and electrode chambers-recorded for the blank assay

compartment, enabling the construction of an experimental breakthrough curve (BTC). Then, by approximating the system to the transport of a solute in a homogeneous saturated porous media, the equilibrium convection-dispersion Eq. (2) was successfully adjusted to the obtained BTC (Fig. 3) using the CXTFIT code (Toride et al. 1995; Fonseca et al. 2009).

$R \partial C / \partial t=D \partial^{2} C / \partial x^{2}-v \partial C / \partial x$

where, $R$ is the retardation factor, $C$ is the $\mathrm{Cr}(\mathrm{VI})$ concentration (in milligrams per liter), $t$ is the elapsed time (in days), $D$ is the dispersion coefficient (in square centimeters per day), $x$ is the distance along the direction of flow (in centimeters) and $v$ is the average pore water velocity (in centimeter per day). CXTFIT code is a program for estimating solute transport parameters from observed concentrations using the convection-dispersion, Eq. 2, as the transport model and a nonlinear least-squares parameter optimization method. The values obtained for the estimated parameters, $R, D$, and $v$, the BTC and the adjusted convectiondispersion, Eq. 2, are shown in Fig. 3. The $R$ values which are relatively higher than 1 express the occurrence of the $\mathrm{Cr}(\mathrm{VI})$ adsorption on the kaolinite (van Genuchten 1981). In contrast, the low value of the pore water velocity reflects the low nonequilibrium effects, which is indicative of the strength of the applicability of the equilibrium selected model to the transport of the $\mathrm{Cr}(\mathrm{VI})$ through the sample under the electric field (Candela et al. 2007). Therefore, in the context of species or mass dispersion, the Peclet number provides information about the transport phenomena in fluid flows.

$P=(\nu L) / D$

where, $P$ is Peclet number, $v$ is the average pore water velocity (in centimeters per day), $L$ is the length (in centimeters) and $D$ is the dispersion coefficient (in square centimeters per day). A

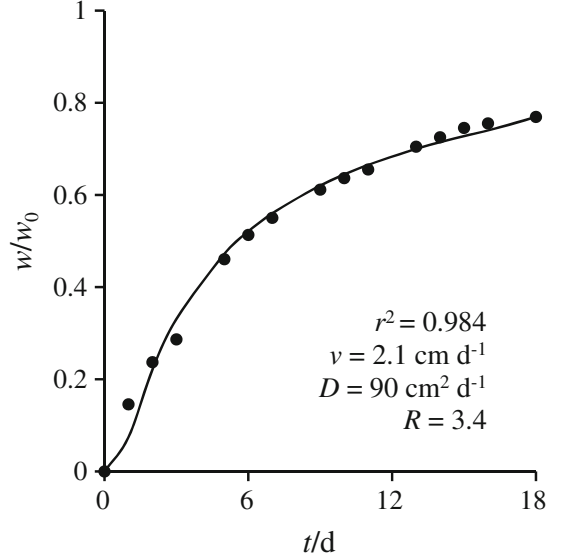

Fig. 3 Equilibrium convection dispersion equation adjusted to the experimental breakthrough curve of the hexavalent chromium normalized weight $\left(w / w_{0}\right)$, concerning the liquid collected at the anode chamber during the blank assay

value of 0.315 was obtained for Peclet number. This value is an indicator of the dispersion predominance in the transport of $\mathrm{Cr}(\mathrm{VI})$ under the electric field, which is in accordance with the distribution of the contaminant after the electrokinetic treatment (Fig. 2) and may result from the counter osmotic flow of water, towards the cathode (Baraud et al. 1997a).

\subsection{Application of a biobarrier}

Based on previous reports (Gupta et al. 2009; Ali 2010), activated carbon was selected as support material. They determined that activated carbon is the best adsorbent able to capture inorganic, as well as organic, pollutants that contaminate water resources. In addition, comparative study using zeolite support to obtain the biobarrier was done. Similarly, as in previous assays, the electrokinetic remediation tests with biobarriers, composed by A. viscosus supported either by activated carbon or zeolite, were carried out for 9 and 18 days.

\subsubsection{Removal and conversion of hexavalent chromium}

In Fig. 4, overall results concerning the conversion $(C \%)$ of the $\mathrm{Cr}(\mathrm{VI})$ to $\mathrm{Cr}(\mathrm{III})$ and the full amount of $\mathrm{Cr}(\mathrm{VI})$ removal $(R \%)$ from the kaolinite are shown. Focusing on the results regarding the assays of 9 days, the little difference between the removal and the conversion of the $\mathrm{Cr}(\mathrm{VI})$ stands out for both biobarriers (A. viscosus immobilized on activated carbon or zeolite). Therefore, in experiments with zeolite support, a conversion of $44 \%$ with a chromium removal of $47 \%$ was obtained. Similar behavior was detected when the support activated carbon was used, achieving a conversion and removal of $17 \%$ and $22 \%$, respectively. These results seem to indicate that almost all the $\mathrm{Cr}(\mathrm{VI})$ removal from the sample was reduced to the trivalent form. 

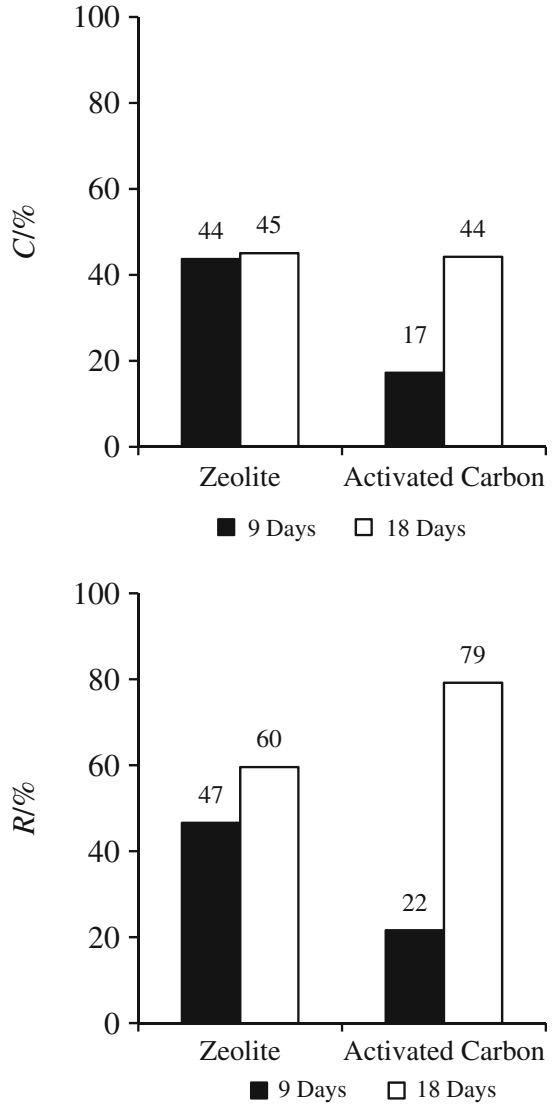

Fig. 4 Conversion $(C / \%)$ define as fraction of hexavalent chromium reduced to the trivalent form and total removal of the hexavalent chromium $(R / \%)$ determined for the assays regarding the both types of biobarriers

When the test period was extended to 18 day, high removal values were achieved in both biobarriers. However, a different behavior was observed in the system which contains the biobarrier with activated carbon. In this case, both values increased greatly, around 2.6- and 3.6-fold, the conversion and removal obtained after 9 days, respectively. The conversion comes up to values similar to the ones obtained with the zeolite and the removal values were the higher recorded in all experiment. Nevertheless, the removal was once more superior to the conversion, denoting that other processes contributed to the decontamination of the soil. In order to clarify these considerations, a closer study was made by analyzing the $\mathrm{Cr}(\mathrm{VI})$ mass distribution through the various sections of the electrokinetic cells regarding the most successful assays (18 day).

\subsubsection{Distribution of the hexavalent and trivalent chromium through the soil columns: $\mathrm{pH}$ dependence}

Figure 5 shows the mass distribution of $\mathrm{Cr}(\mathrm{VI})$ and $\mathrm{Cr}(\mathrm{III})$ according to the type of biobarrier coupled to the electrokinetic treatment, zeolite (A) or activated carbon (B). In this
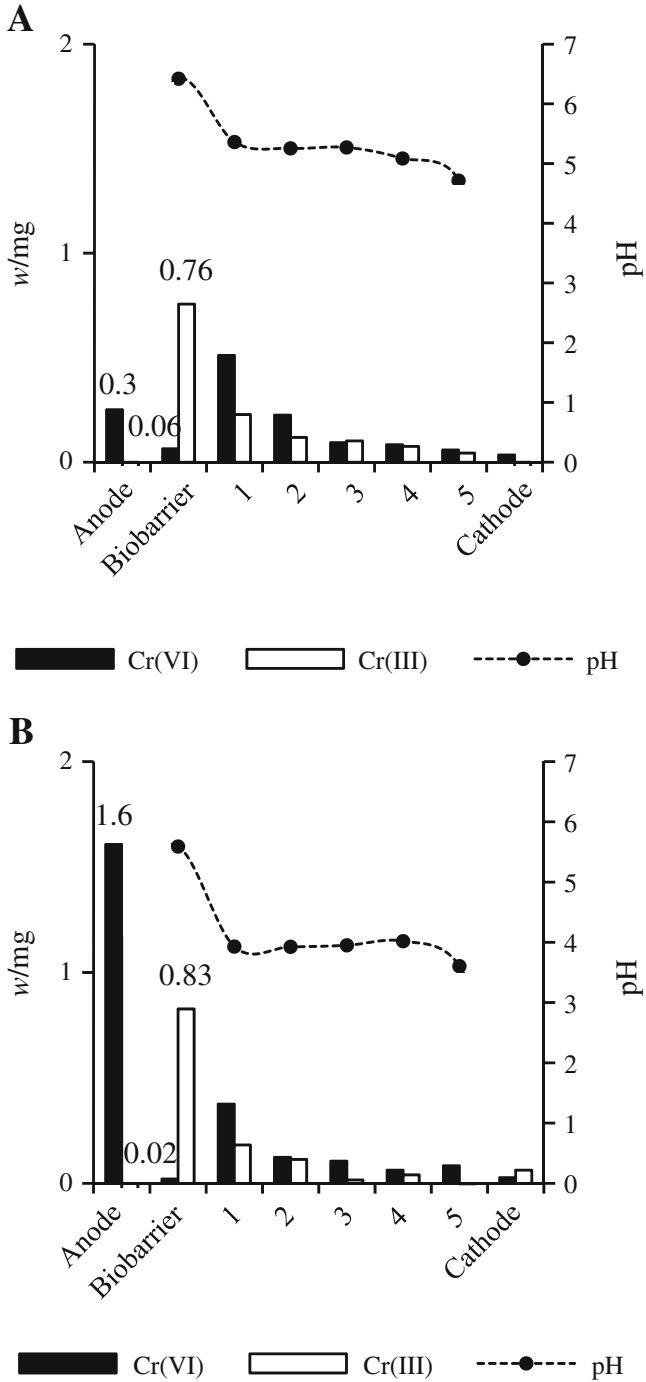

Fig. 5 Chromium mass $(w / \mathrm{mg})$ and $\mathrm{pH}$ distribution observed for the assays with both type of biobarriers. a Zeolite supported biobarrier. b Activated carbon supported biobarrier

study, the mass distribution in electrode chambers, biobarrier and five soil samples (S1 to S5) were evaluated. The high level of Cr (III) retained in both biobarriers is noticeable, around 0.76 and 0.83 for zeolite and activated carbon support, respectively. These results are due to the bacterium A. viscosus, which is a great producer of exopolysaccharides, which confers to the bacteria the ability for adhesion to a support and also enhances its metal retention capacity. Additionally, this bacterium is recognized as a reducer of $\mathrm{Cr}(\mathrm{VI})$ to $\mathrm{Cr}(\mathrm{III})$. Therefore, and according to the "adsorption coupled reduction" theory, the trivalent cations were effectively entrapped in both supports after de $\mathrm{Cr}(\mathrm{VI})$ reduction, explaining the high levels of this cation in both biobarriers (Silva et al. 2008, 2009; Figueiredo et al. 2010a). Nevertheless, the mass of $\mathrm{Cr}(\mathrm{III})$ decreased from the biobarrier to the cathode, highlighting the release and consequent 
movement of these cations towards this section as a result of the electric field applied. This behavior is in accordance with the model transport determining in the blank assays, in which the predominance of dispersion revealed the counter osmotic flow of water, towards the cathode.

Therefore, the detected amount of $\mathrm{Cr}(\mathrm{VI})$ in the anode chamber with the biobarrier containing activated carbon was higher for the assay of 18 days ( $1.6 \mathrm{vs} 0.3 \mathrm{mg}$ ). This probably occurred due to the saturation of the biobarrier with $\mathrm{Cr}(\mathrm{III})$ and consequent transport of $\mathrm{Cr}(\mathrm{VI})$ across it, having more predominant in this biobarrier due to its higher porosity and specific area. It is important to note that for this specific system, the increase of the test period enhanced the conversion and as more $\mathrm{Cr}(\mathrm{VI})$ the biobarrier reached being effectively dispersed on it. In fact, observing Fig. 5, it is evident that the highest mass of $\mathrm{Cr}(\mathrm{III})(0.83 \mathrm{vs} 0.76 \mathrm{mg}$ ) was determined for the biobarrier composed with activated carbon. This result is due to the higher compaction of the zeolite biobarrier that interfered the ionic migration of the $\mathrm{Cr}$ (VI) oxyanions, but also its dispersion through the biobarrier, affecting negatively the conversion, even for the elongated the treatment time. This small difference between the mass of $\mathrm{Cr}(\mathrm{III})$ determined in both biobarriers and the $\mathrm{Cr}$ (VI) determined in the anodes chambers permit to conclude that the conversion efficiency is very close for both types of biobarriers, but due to its highest porosity, the activated carbon biobarrier promotes an higher removal of $\mathrm{Cr}(\mathrm{VI})$, after the saturation of the barrier matrix with $\mathrm{Cr}(\mathrm{III})$.

The $\mathrm{pH}$ determined across the soil showed the same tendency for both tests, and varied between 3.9 and 5.4, for the soil sections. The slight increasing $\mathrm{pH}$ in the direction of the anode chamber may also explain the increasing quantities of $\mathrm{Cr}(\mathrm{VI})$ in the same direction, as its mobility tends to increase with the $\mathrm{pH}$. The highest $\mathrm{pH}$ values determined in the biobarriers was 6.4 for the zeolite and 5.6 for the activated carbon. These values are clearly related with the supports nature, as both increase the $\mathrm{pH}$ in the medium, with more expression for the zeolite (Ouki and Neufeld 1997; Pazos et al. 2010).

Chromium, which may exist as $\mathrm{HCrO}^{4-}, \mathrm{Cr}_{2} \mathrm{O}_{7}{ }^{2-}$, etc., in solution has a tendency to bind the protonated active sites of the sorbent. In several previous researches, the effect of $\mathrm{pH}$ on chromium adsorption was studied. Although, the equilibrium chromium sorption is favored by acidic $\mathrm{pH}$ range, the optimal value depends on the nature of the support nature. Gupta and Rastogi (2009) studied the adsorption on raw and acid-treated forms of Oedogonium hatei algal biomasses and they determined that $\mathrm{pH}$ increases, algal cell wall becomes more and more negatively charged due to functional groups, which repulse the negatively charged chromate ions thereby affecting $\mathrm{Cr}(\mathrm{VI})$ adsorption on the algal surface. However, when the cyanobacterium Nostoc muscorum was used, the removal of $\mathrm{Cr}(\mathrm{VI})$ takes place even above pH 3.0 (Gupta and Rastogi 2009). On the other hand, when bagasse fly ash was used the maximum uptake of chromium took place at pH 5.0 (Gupta and Ali 2004) which indicates involvement of some other metal binding mechanism such as physical adsorption or ion exchange mechanism at higher $\mathrm{pH}$ and confirm the influence of the sorbent nature.

According to the "adsorption coupled reduction" theory, after the $\mathrm{Cr}(\mathrm{VI})$ sorption, it is reduced to $\mathrm{Cr}(\mathrm{III})$ and effectively entrapped in the support. The $\mathrm{pH}$ range (4-6) was reported by Mohan et al. (2006) as the optimum for the sorption of $\mathrm{Cr}(\mathrm{III})$ on carbon surface, as this presented a negative charge and all the $\mathrm{Cr}(\mathrm{III})$ species were cationic. Therefore, the adsorption process was classified as an electrostatic attraction between the ionized acid sites of the activated carbon and the $\mathrm{Cr}$ (III) cations. Wu et al. (2008) studied the sorption of $\mathrm{Cr}(\mathrm{III})$ onto a zeolite in the $\mathrm{pH}$ range (2.5-9.0) and noted an increase tendency till a pH of 6.5. As zeolites have permanent negative charge, the sorption of $\mathrm{Cr}$ (III) above its solubility limit $(\mathrm{pH}=4.71)$ was attributed to the precipitation of the metal hydroxides on the surface of
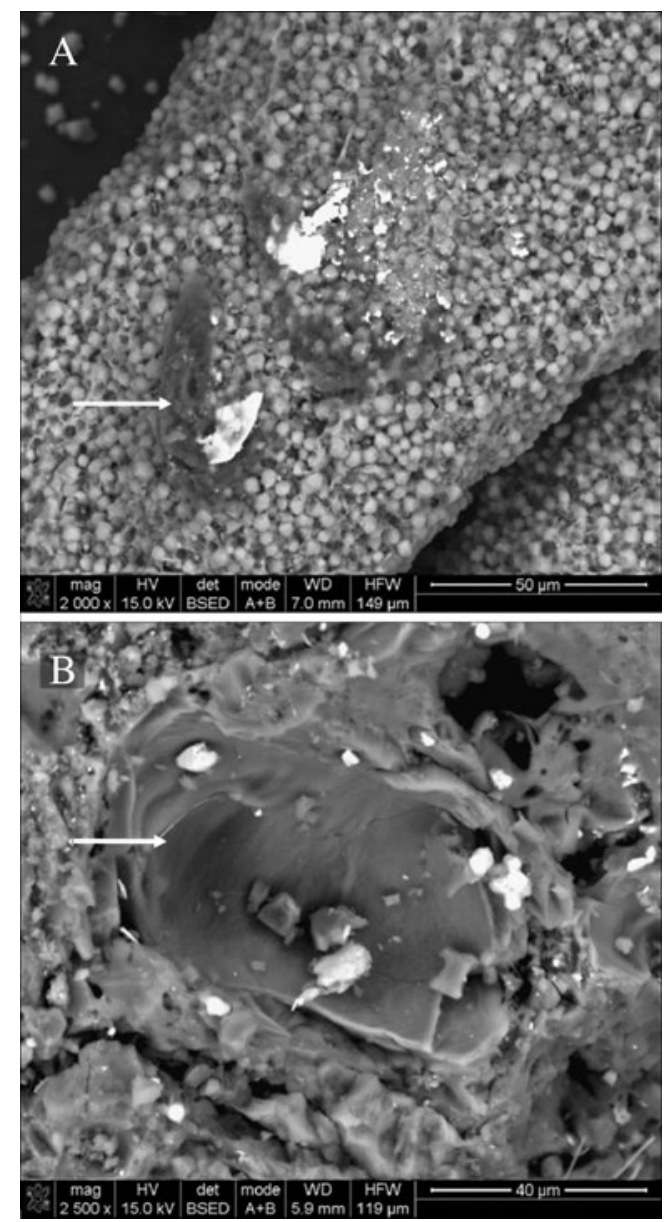

Fig. 6 SEM images of the biobarriers after the combined treatment. The arrows are pointing the biomass adhered to each support. a Zeolite supported biobarrier. b Activated carbon supported biobarrier 
the zeolite (Silva et al. 2008). In fact, this phenomenon may have occurred in both supports used in this study.

\subsubsection{Biobarriers uptake and microorganisms viability}

The aforementioned results revealed that the mass of $\mathrm{Cr}$ (III) retained in the biobarrier with activated carbon was superior to the mass of $\mathrm{Cr}$ (III) retained by the zeolite biobarrier. Although the difference between the total mass of $\mathrm{Cr}$ (III) retained by both biobarriers $(0.07 \mathrm{mg})$ was not that significant, the value of uptake, relative to the total chromium, was considerably higher for the activated carbon biobarrier, $0.074 \mathrm{vs}$ $0.048 \mathrm{mg} \mathrm{g}^{-1}$. This is clearly related with the difference between the bulk densities and specific areas of the supports. Activated carbon has a lower density and a higher specific area than zeolite. In addition, the uptake is determined with respect to the total chromium and consequently the difference between the $\mathrm{Cr}(\mathrm{VI})$ retained in each biobarrier (Fig. 5) should also influence their values. In fact, the activated carbon has more ability to retain the $\mathrm{Cr}(\mathrm{VI})$ oxyanions on its positively charged sites, generated by the liberation of $\mathrm{OH}^{-}$ions during the reaction with water (Ouki and Neufeld 1997):

$$
\mathrm{C}_{x} \mathrm{O}_{2}+\mathrm{H}_{2} \mathrm{O}=\left[\mathrm{C}_{x} \mathrm{O}\right]^{2+}+2 \mathrm{OH}^{-}
$$

After the assays, the biobarriers were tested for the adhesion and bioviability of the A. viscosus by means of SEM analysis and growth on solid media, respectively. The SEM analysis allows observing the biomass adsorbed to each support (Fig. 6). In addition, the microorganism was positively grown on the agar plates, revealing a high resistance to the $\mathrm{Cr}(\mathrm{VI})$ tested levels and to the electric field action.

\section{Conclusions}

In this work, two types of permeable reactive biobarriers, $A$. viscosus immobilized on activated carbon and zeolite supporting, were efficiently coupled to electrokinetic treatment to treat soil polluted with $\mathrm{Cr}(\mathrm{VI})$. The study of the chromium mobility revealed the predominance of dispersion in the transport of $\mathrm{Cr}(\mathrm{VI})$ under the electric field, which is due to the counter osmotic flow of water, towards the cathode. Similar conversion of $\mathrm{Cr}(\mathrm{VI})$ to $\mathrm{Cr}(\mathrm{III})$ (approx. 45\%) and similar retention of $\mathrm{Cr}$ (III) (approx. $0.8 \mathrm{mg}$ ) were found for zeolite and activated carbon systems. However, the system with activated carbon showed higher uptake $\left(0.074 \mathrm{mg} \mathrm{g}^{-1}\right)$ and removal (79\%). Therefore, the viability of the new coupling technology developed (electrokinetic + biobarriers) to treat low-permeability polluted soils was demonstrated. Based on the proved efficiency, this novel remediation technique has to be optimized and applied to real soils in order to validate it as a large-scale solution.
Acknowledgments This work was supported by the Spanish Ministry of Science and Innovation (CTQ2008-03059/PPQ), Xunta de Galicia (08MDS034314PR). The authors are grateful to the Spanish Ministry of Science and Innovation for providing financial support for Marta Pazos under the Ramón y Cajal program and the Fundação para a Ciência e Tecnologia, Ministério da Ciência e Tecnologia, Portugal through the $\mathrm{PhD}$ grant of Bruna Fonseca (SFRH/BD/27780/2006).

\section{References}

Alcantara MT, Gomez J, Pazos M, Sanroman MA (2008) Combined treatment of PAHs contaminated soils using the sequence extraction with surfactant-electrochemical degradation. Chemosphere $70: 1438-1444$

Ali I (2010) The quest for active carbon adsorbent substitutes: inexpensive adsorbents for toxic metal ions removal from wastewater. Sep Purif Rev 39:95-171

Ali I, Gupta VK (2007) Advances in water treatment by adsorption technology. Nat Protoc 1:2661-2667

Ali I, Khan TA, Asim M (2011) Removal of arsenic from water by electrocoagulation and electrodialysis techniques. Sep Purif Rev 40:25-42

Baraud F, Fourcade MC, Tellier S, Astruc M (1997a) Modelling of decontamination rate in an electrokinetic soil processing. Int $\mathrm{J}$ Environ Anal Chem 68:105-121

Baraud F, Tellier S, Astruc M (1997b) Ion velocity in soil solution during electrokinetic remediation. J Hazard Mater 56:315-332

Boni MR, Sbaffoni S (2009) The potential of compost-based biobarriers for $\mathrm{Cr}(\mathrm{VI})$ removal from contaminated groundwater: column test. J Hazard Mater 166:1087-1095

Candela L, Álvarez-Benedí J, Condesso de Melo MT, Rao PSC (2007) Laboratory studies on glyphosate transport in soils of the Maresme area near Barcelona, Spain: transport model parameter estimation. Geoderma 140:8-16

Cristani M, Naccari C, Nostro A, Pizzimenti A, Trombetta D, Pizzimenti F (2011) Possible use of Serratia marcescens in toxic metal biosorption (removal). Environmen Sci Pollut Res 1-8

Fendorf SE (1995) Surface reactions of chromium in soils and waters. Geoderma 67:55-71

Figueiredo H, Silva B, Quintelas C, Neves IC, Tavares T (2010a) Effect of the supporting zeolite structure on $\mathrm{Cr}$ biosorption: performance of a single-step reactor and of a sequential batch reactor - a comparison study. Chem Eng J 163:22-27

Figueiredo H, Silva B, Quintelas C, Pereira MFR, Neves IC, Tavares T (2010b) Biosorption of hexavalent chromium based on modified Y zeolites obtained by alkali-treatment. Environ Eng Manag J 9:305-311

Figueiredo H, Silva B, Quintelas C, Raposo MMM, Parpot P, Fonseca AM, Lewandowska AE, Bañares MA, Neves IC, Tavares T (2010c) Immobilization of chromium complexes in zeolite $\mathrm{Y}$ obtained from biosorbents: synthesis, characterization and catalytic behaviour. Appl Catal Environ 94:1-7

Fonseca B, Teixeira A, Figueiredo H, Tavares T (2009) Modelling of the $\mathrm{Cr}(\mathrm{VI})$ transport in typical soils of the North of Portugal. J Hazard Mater 167:756-762

Gupta VK, Ali I (2004) Removal of lead and chromium from wastewater using bagasse fly ash-a sugar industry waste. J Colloid Interface Sci 271:321-328

Gupta VK, Rastogi A (2008) Sorption and desorption studies of chromium(VI) from nonviable cyanobacterium Nostoc muscorum biomass. J Hazard Mater 154:347-354

Gupta VK, Rastogi A (2009) Biosorption of hexavalent chromium by raw and acid-treated green alga Oedogonium hatei from aqueous solutions. J Hazard Mater 163:396-402 
Gupta VK, Mohan D, Sharma S, Park KT (1999) Removal of chromium (VI) from electroplating industry wastewater using bagasse fly ash - a sugar industry waste material. Environmentalist 19:129-136

Gupta VK, Gupta M, Sharma S (2001) Process development for the removal of lead and chromium from aqueous solutions using red mud - an aluminium industry waste. Water Res 35:1125-1134

Gupta VK, Jain AK, Kumar P, Agarwal S, Maheshwari G (2006) Chromium(III)-selective sensor based on tri-o-thymotide in PVC matrix. Sens Actuators B: Chem 113:182-186

Gupta VK, Carrott PJM, Ribeiro Carrott MML, Suhas (2009) Low-cost adsorbents: growing approach to wastewater treatment - a review. Crit Rev Environ Sci Technol 39:783-842

Gupta VK, Rastogi A, Nayak A (2010) Adsorption studies on the removal of hexavalent chromium from aqueous solution using a low cost fertilizer industry waste material. J Colloid Interface Sci 342:135-141

Gupta VK, Agarwal S, Saleh TA (2011) Chromium removal by combining the magnetic properties of iron oxide with adsorption properties of carbon nanotubes. Water Res 45:2207-2212

Kanagaraj J, Mandal AB (2011) Combined biodegradation and ozonation for removal of tannins and dyes for the reduction of pollution loads. Environ Sci Pollut Res. 1-11

Machado MD, Soares EV, Soares HMVM (2011) Selective recovery of chromium, copper, nickel, and zinc from an acid solution using an environmentally friendly process. Environ Sci Pollut Res 18:1279-1285

Mohan D, Singh KP, Singh VK (2006) Trivalent chromium removal from wastewater using low cost activated carbon derived from agricultural waste material and activated carbon fabric cloth. J Hazard Mater 135:280-295

Ouki SK, Neufeld RD (1997) Use of activated carbon for the recovery of chromium from industrial wastewaters. J Chem Technol Biotechnol 70:3-8

Pazos M, Gouveia S, Sanroman MA, Cameselle C (2008) Electromigration of $\mathrm{Mn}, \mathrm{Fe}, \mathrm{Cu}$ and $\mathrm{Zn}$ with citric acid in contaminated clay. J Environ Sci Health, Part A: Tox Hazard Subst Environ Eng 43:823831

Pazos M, Alcántara MT, Cameselle C, Sanromán MA (2009) Evaluation of electrokinetic technique for industrial waste decontamination. Sep Sci Technol 44:2304-2321

Pazos M, Branco M, Neves IC, Sanromán MA, Tavares T (2010) Removal of $\mathrm{Cr}(\mathrm{VI})$ from aqueous solutions by a bacterial biofilm supported on zeolite: Optimisation of the operational conditions and scale-up of the bioreactor. Chem Eng Technol 33:2008-2014

Priyantha N, Bandaranayaka A (2011) Interaction of Cr(VI) species with thermally treated brick clay. Environ Sci Pollut Res 18:75-81
Quintelas C, Tavares T (2001) Removal of chromium(VI) and cadmium(II) from aqueous solution by a bacterial biofilm supported on granular activated carbon. Biotechnol Lett 23:1349-1353

Quintelas C, Fernandes B, Castro J, Figueiredo H, Tavares T (2008) Biosorption of $\mathrm{Cr}(\mathrm{VI})$ by three different bacterial species supported on granular activated carbon - a comparative study. J Hazard Mater 153:799-809

Quintelas C, Fonseca B, Silva B, Figueiredo H, Tavares T (2009) Treatment of chromium(VI) solutions in a pilot-scale bioreactor through a biofilm of Arthrobacter viscosus supported on GAC. Bioresour Technol 100:220-226

Reddy KR, Chinthamreddy S (2003) Effects of initial form of chromium on electrokinetic remediation in clays. Adv Environ Res 7:353-365

Silva B, Figueiredo H, Quintelas C, Neves IC, Tavares T (2008) Zeolites as supports for the biorecovery of hexavalent and trivalent chromium. Microporous Mesoporous Mater 116:555-560

Silva B, Figueiredo H, Neves IC, Tavares T (2009) The role of pH on $\mathrm{Cr}(\mathrm{VI})$ reduction and removal by Arthrobacter viscous. Int $\mathrm{J}$ Chem Biol Eng 2:100-103

Singh AK, Gupta VK, Gupta B (2007) Chromium(III) selective membrane sensors based on Schiff bases as chelating ionophores. Anal Chim Acta 585:171-178

Teutli-León MM, Oropeza MT, González I, Soria A (2005) Mathematical modeling of a galvanostatic soil electroremediation process. AICHE J 51:1822-1833

Toride N, Leij FJ, van Genuchten MT (1995) The CXTFIT code for estimating transport parameters from laboratory or field tracer experiments. U.S. Salinity Laboratory, U.S. Department of Agriculture, Riverside

USEPA (1992) Chromium, hexavalent (colorimetric). 7196A. USEPA

USEPA (1996) Alkaline digestion for hexavalent chromium. 3060A. USEPA

USEPA (2004) Soil and waste pH. Method 9045D. USEPA

USEPA (2007) Microwave assisted acid digestion of sediments, sludges, soils, and oils. 3051. USEPA

van Genuchten MT (1981) Non equilibrium transport parameters from miscible displacement experiments. U.S. Salinity Laboratory, U. S. Department of Agriculture, Riverside

Viamajala S, Peyton BM, Gerlach R, Sivaswamy V, Apel WA, Petersen JN (2008) Permeable reactive biobarriers for in situ $\mathrm{Cr}(\mathrm{VI})$ reduction: bench scale tests using Cellulomonas sp. strain ES6. Biotechnol Bioeng 101:1150-1162

Wu D, Sui Y, He S, Wang X, Li C, Kong H (2008) Removal of trivalent chromium from aqueous solution by zeolite synthesized from coal fly ash. J Hazard Mater 155:415-423 